To cite: Rangaswamy, N., \& Arora, P. (2015). The mobile internet in the wild and every day: Digital leisure in the slums of urban India, International Journal of Cultural Studies, 1-16.

\title{
The mobile internet in the wild and every day: Digital leisure in the slums of urban India
}

\section{International Journal of Cultural Studies, 1-16}

\author{
Nimmi Rangaswamy \\ Xerox Research Centre, India \\ Indian Institute of Technology (IIT), Hyderabad, India
}

\section{Payal Arora}

Erasmus University Rotterdam, The Netherlands

\begin{abstract}
The wild and the everyday point at once to twinned aspects of life and, in this article, to a technological imaginary drawing upon the use of the mobile internet in urban slums of India. The article responds to the rather untethered way, from the point of view of state regulation, in which the telecom market in India has devolved to include poor populations, stoking a repertoire of unconventional daily use of the internet by youth living in slums. This article serves to locate the 'wild and everyday' as a specific sociocultural space in relation to use of mobile Facebook among young populations invisible to mainstream research on internet and culture. While development, as conventionally understood, is not focused on purposive outcomes of digital leisure practice (romance, play, entertainment), we argue that online engagements such as these are powerful precursors to ecologies of learning, reconstituting our understandings of global and mobile internet practice.
\end{abstract}

\section{Keywords}

culture, entertainment, imaginaries, India, leisure, mobile internet, play, poor, slums, youth

\section{INTRODUCTION}

The wild and the everyday point at once to twinned aspects of life and, in this paper, to a technological imaginary drawing upon the use of the mobile internet in urban slums of India.

The paper responds to the rather untethered way, from the point of view of state regulation, in which the telecom market in India has devolved to include poor populations stoking a repertoire of unconventional daily use of the internet by youth living in slums. This paper serves 
To cite: Rangaswamy, N., \& Arora, P. (2015). The mobile internet in the wild and every day: Digital leisure in the slums of urban India, International Journal of Cultural Studies, 1-16.

to locate the 'wild and everyday' as a specific sociocultural space in relation to use of the internet and social media technologies among populations invisible to mainstream research on mobile society and culture. We specifically point to the internet offering a free zone in resource- poor settings, untethering slum youth from social constraints to explore and present self-identity. In uncovering ' the wild and everyday ' of internet use, this paper goes beyond developmental approaches to technology use, usually reserved to understand underprivileged and marginal populations, by vesting agency of technology use for pleasure and leisure in a similar population segment of slum youth

While development, as is commonly understood, is not focused on purposive outcomes of informal learning, we argue that engagements such as these are a powerful precursor to developing technology literacies, skills and ecologies of learning (Rangaswamy, 2013). To examine the accretion of digital literacies through leisure practices in the everyday we leverage evidence embedded in the social life of things, the mundane use of technology as an extremely immersive and schooling experience. The search for and enjoyment of leisure-driven content, inform the 'stuff' of digital technologies shaping relationships between people, digital media, and informal learning. It's indeed astounding to find relative affluence in the uptake of digital technologies by user populations least likely to afford and access them in the slums of urban India. With a focus on Facebook via mobile use among the youth, mostly young adult \& male, in the slums of Hyderabad and Chennai, the themes we explore to frame this paper will be a departure from research approaches studying 'perpetually connected' (Katz \& Aakhus 2002) spaces and persons in the domain of new media youth practices (Ito et al 2009, boyd 2008). It is 
To cite: Rangaswamy, N., \& Arora, P. (2015). The mobile internet in the wild and every day: Digital leisure in the slums of urban India, International Journal of Cultural Studies, 1-16.

interesting to note Goggin's [2009] study of the iPhone underscoring the active role consumers' play in orchestrating a specific culture of mobile phone use. Like the iPhone, slum youth in our study remake their humble phones as an 'instance of consuming culture' but in ways that draw meaning from their specific social contexts.

Social Network Sites (SNS) are purposed to enable new communication channels, architecting novel ways of acquainting with people and managing flows of interpersonal relationships. With more than a billion users, is Facebook all about a new relationship between society and technology? As digital multi-media permeates the globe and as more people are spurred to go online, we are seeing the steady narrowing of literacy gaps between the digital rich and poor especially among users who have the infrastructural support to forge 'perpetual contact' and those who lack them to access, use and persist with digital media. Facebook in India, the third largest global market with over 90 million users, is steadily immersing populations at the lower economic spectrum, allowing a hitherto unavailable trans-hierarchical class/caste social experience. The ways that these constrained users are being acculturated into Facebook and into the global community are subtle, layered and culturally coded. While our young informants, by joining Facebook, seem to have been introduced simultaneously to the internet and its many affordances, they reported learning English, typing with a keyboard, developing sociable personalities and acquiring general knowledge via Facebook mediated interactions. More powerful themes of idealizations of social qualities such as romantic relationships, persona building, communication/ netiquette patterns, emerged as we dwelled deeper into both the manifest on-line behaviors and the ethnographic off-line contexts 
To cite: Rangaswamy, N., \& Arora, P. (2015). The mobile internet in the wild and every day: Digital leisure in the slums of urban India, International Journal of Cultural Studies, 1-16.

intermediating social media use. This work serves as an opportunity to re-situate notions of digital labor and prosumption that are for the most part, driven by Western concerns and values. Our insights strongly suggest an aspirational appropriation of Facebook beyond the more grounded and local social affordances, a small example being friending young women of a higher class and from international locations. Not only is social media familiarizing these aspirations, but offering a new materiality to view and articulate a global aesthetic and life chances in unaccustomed, sometimes revolutionary ways. Our approach to everyday Facebook use in urban South Indian slums is exploring reformulations of material and conceptual ideas about one's social location, the subversion of these in friending patterns, in the extending of potential romantic opportunities and the experiencing of aspirational mobility. Much of our interest lies in the ways Facebook is becoming a critical virtual setting in contesting and overshadowing handed-down versions of conventional notions of personhood, social esteem, markers of social location, communities of friendship and heterosexual love.

\section{FOREGROUNDING FRAMES OF REFERENCE}

\section{Revisiting ICTs as artifacts of Development}

Despite the broad and liberal definition, the ICT for development community (ICTD) tends to privilege what are and what are not desired/legitimate developmental impacts of technology. New media practice in emerging economies that are substantively oriented towards leisure play, entertainment and pleasure, are duly relegated as anecdotal. However, some of us in the 
To cite: Rangaswamy, N., \& Arora, P. (2015). The mobile internet in the wild and every day: Digital leisure in the slums of urban India, International Journal of Cultural Studies, 1-16.

ICTD domain view development as enhancement of livelihoods/quality of life reflected in improved life indices and adopt familiar ways to identify technology driven processes implicating progress (Arora \& Rangaswamy, 2013; 2014; Ganesh, 2010; Mitra, 2005; Kavoori, Chadha \& Arceneaux, 2006). In this paper, we move away from a narrow focus of ICTs as objects of development; instead, we support the idea of these tools as social artifacts of the $21^{\text {st }}$ century that are often deeply entrenched in leisure made evident through its everyday usage in the global South. It is essential to complicate the linear understanding of socioeconomic progress, development benefits and beneficiaries, particularly the normative understanding of 'users' in emerging economies as unique and utilitarian beings in this digital age. By repositioning these users within the larger rubric of social mediatization, the authors argue that this facilitates a bi-directional flow of scholarship between New Media Studies and ICTD fields. This fluidity enables ICTD scholars to contribute to contemporary and critical preoccupations within internet studies regarding online surveillance and privacy, virtual economies and free labor, and cyber-activism to name a few, and in turn, provide a rich diversity and representation of participatory practice that extends digital understandings beyond the Western frame of reference.

Digital Empowerment can mean a variety of things in different contexts. To begin with a globally accredited definition, the World Bank continues to understand empowerment as, “... the process of increasing the capacity of individuals or groups to make choices and to transform those choices into desired actions and outcomes. Central to this process are actions which both build individual and collective assets....". This simply translates to empowerment as a decision- 
To cite: Rangaswamy, N., \& Arora, P. (2015). The mobile internet in the wild and every day: Digital leisure in the slums of urban India, International Journal of Cultural Studies, 1-16.

making power to own, use and allocate available socio-economic resources. Initiatives, motivated by individual or social impulses, illustrate how individuals can choose to act to seize an economic or social opportunity at a given time. We are not advocating an either/or approach to choice as it is demonstrated that these new participatory platforms can fulfill multiple agendas and are capitalized accordingly. So we see nurses in emerging economies use SMS to remind people to take their anti-retrovirals as well as make private phone calls to their loved ones; we see farmers check for updated crop prices online while also using the digital platform to fulfill sexual desires (Ganesh, 2010). In a place like the urban slum, formal schooling is no longer the lone gatekeepers of learning and organic collaborative environments become important to infusing access and building digital literacies. A case in point is the new digital literacies created by children in the slum to mediate play with novel computer applications (Mitra 2002). Several of the authors own research studies have dwelt on very specific cultural productions of technology localizations in India which involved a spectrum of leisure practices: the multi-purpose peri-urban cyber café, the mobile retail and repurpose store, the urban slum mobile internet hub, and the rural community information centers are a few such examples validating this avenue of research (Rangaswamy, 2008, 2010; Arora, 2010; 2010a). Many of these socio-technical instantiations occur as, what we believe, a forging of local competence. If competence is defined as having sufficient knowledge or skills to act effectively in a given context, everyday ICTs bracket and hone that competence to tackle practical and real world experiences of technology. For example rather than using the internet to search for educational material, low-income youth in Kenya search for music and movie 
To cite: Rangaswamy, N., \& Arora, P. (2015). The mobile internet in the wild and every day: Digital leisure in the slums of urban India, International Journal of Cultural Studies, 1-16.

teasers (Wyche 2013); A mobile store in a Mumbai slum can make more money from downloading audio-visual content than selling SIM cards (Arora, 2010); a shared internet centre in small town Ecuador supports itself transferring ringtones to mobile phones (Salvador et al 2005); cybercafés in rural Himalayas survive primarily because of the use of Orkut by the local teens (Rangaswamy, 2010). These are hardly developmental from a conservative ICTD perspective but are critical spaces offering entry, experimentation and ultimately immersions of use.

\section{The Social Life of ICTD}

ICTs are social artifacts before they are baptized as tools for development. Using the titular idea in Appadurai's seminal work, The Social life of things (1988) we examine the influence of technology in the formations of cultural extensions of technology use. Over the past decade, as technologies migrate and re-home in the global South, they come to be contextually imagined, accepted, modified, and operated (Rangaswamy, 2011). Such trajectories of technology use have little ideological space to evolve and be recognized as legitimate processes through the lens of development. An emerging class of literature has presented accounts of technology usage in the south wherein leisure practice is interwoven and intricately embedded; in middleclass homes in Asia (Bell 2006, Donner et al 2008), technology ecologies of microentrepreneurs in South Africa (Donner 2009), Bluetooth enabled sharing of digital content among the Bangalore street entrepreneurs (Smyth et al 2010), digital browsing in cybercafés in rural Himalayas (Arora 2010), sexuality and the internet in emerging markets (Ganesh 2010), 
To cite: Rangaswamy, N., \& Arora, P. (2015). The mobile internet in the wild and every day: Digital leisure in the slums of urban India, International Journal of Cultural Studies, 1-16.

and digital learning through play (Mitra 2002; 2003). For ICTs to become tools of utility they often undergo a process of sustained exploration through leisure avenues. We see this pattern recurring with every new technology of the time from the radio, the television to the computer in our day and age (Arcangeli 2003; Bryce 2001; Fischer 1994; MacLean 1968). Much of the ethnographic work amongst populations in low-income, digitally unstable, and diverse literate environments is about getting closer to the processes of cultural production of global technologies. Local translations define the relationships between the broad understanding of technology, deemed for specific use, and the practices occurring around them in a specific social ecology. Therefore, development practitioners need to confront the mutuality of the global and local influence on competence, literacy and skill building and also reveal mediating relationships between accessing and adopting technology.

The impact of internet-based technologies of the self in early studies of virtual communities, in the arrival of the Web 2.0 and networked forms of communication and information through digital social media have emphasized transformations in notions of community, identity, and the nature of human interactions (Castells, 2000; Miller \& Slater, 2000; Wellman \& Haythornthwaite, 2002; Turkle 1995) Many of the changes arising within a new media ecology can be captured through the concept of "prosumption." Defined as the collapse or convergence of production and consumption, prosumption highlights how users (formally seen as passive consumers) both create and consume their own media content (Ritzer \& Jurgenson, 2010 in Horst \& Wallis 2011). Some of the examples intersecting the domains of technologies for the self and ICT for development are also intersections of instrumental 
To cite: Rangaswamy, N., \& Arora, P. (2015). The mobile internet in the wild and every day: Digital leisure in the slums of urban India, International Journal of Cultural Studies, 1-16.

consumption with leisure oriented appropriations. Referred as "smart consumption" (Alhassan, 2004), or the strategic use of mobile phones through practices such as flashing and text messaging (Sey 2010), these are practices designed to optimize means for pursuing a rich repertoire of mobile communication channels.

Practices of self are ways in which the subject actively constitutes herself (Foucault 1988) and by extension, alludes to a suite of technologies that permit individuals to instrumentalise the self towards a better state of being (Bakardjieva \& Gaden 2012). The internet offers a platform of resources for the active and reflexive shaping of the self, a central feature characterizing the era of the Web 2.0 and the everyday of the local-global dialectic, and the other dialectic between technology platforms and users practices inscribing a parallel life. A study of MySpace profiles, for example, documents the function of this site as a stage for the performance of taste (Liu 2007 in Bakardjieva \& Gaden 2012). This is an activity in which the self is being expressed in terms of the semiotic systems of popular culture such as music, film, television, clothing and so forth. The user interface of MySpace invokes directly the symbols of this culture and users write themselves into MySpace by mapping themselves to the dictates of the site's cultural taste. Newer forms of publishing such as YouTube are ways to narrate and communicate experiences as consumers and with incremental use and user created practices, values associated with specific user communities of the platform begin to emerge. In a study of YouTube, Burgess and Green [2009] indicate the workings of a platform as a cultural system, a virtual affordance of a continuum of cultural participation. In a sense YouTube is a technology of performance and user driven activity that creates and sustains the popularity and visibility of 
To cite: Rangaswamy, N., \& Arora, P. (2015). The mobile internet in the wild and every day: Digital leisure in the slums of urban India, International Journal of Cultural Studies, 1-16.

content creators [Arora \& Rangaswamy, 2013; 2014; 2014a]. Like all media YouTube makes sense only when people make use of in everyday life [Burgress \& Green].

In our research we are seeing a simultaneous interplay of affordances and constraints exerted by technologies of self, at once cutting-edge and ominous for users at the margins of participation. How is Facebook in the Indian slums configuring the youth understanding of globalization, diasporas, communication ecologies, self-identity, heterosexual romance, in short their habitus? As Doron remarks, in his study of Mobile phones and mobility in the context of a bustling religious-cultural urban space in India, by creating 'stuff' (Miller 2010) we simultaneously create ourselves in varied and contradictory ways. These can produce liberating or oppressive effects depending on the cultural and historical contexts but constitute a dynamic site for the development of human social and material relation.

\section{The Culture of Aspiration as prelude to Development}

The idea of aspiration told by Appadurai (2004) as the capacity to aspire is also a tool kit to understand the relationship between culture, poverty and development. For the most part, Appadurai argues, it is in the realm of culture that ideas of the future, as much as those about the past, are embedded and nurtured. Thus, in strengthening the capacity to aspire, conceived as a cultural capacity, especially among the poor, the future-oriented logic of development could find a natural ally, and the poor could find the resources required to contest and alter the conditions of their own poverty. This argument runs against the ICTD grain of many 'deepseated images' of the opposition of culture to economy. But it offers a new foundation on 
To cite: Rangaswamy, N., \& Arora, P. (2015). The mobile internet in the wild and every day: Digital leisure in the slums of urban India, International Journal of Cultural Studies, 1-16.

which research can base answers to two basic questions: why is culture a capacity worth building and strengthening and what are the concrete ways in which it can be strengthened? This nuanced approach to aspiration is also tied to the author's idea of production of locality and the idea of imagination as social practice not just defined by reproductive logics (aka Bourdieu's rules \& regularities) but as collective/social visions or desires. To produce is to inhabit and sustain a space, a relation involving large amounts of labour, attention and effort. Here, poverty is not only a condition but is how people view themselves as poor and as a group in society including the awareness of being poor in the language that society offers to articulate this condition. Hence, the poor certainly have understandings of themselves and the world which are expressed in and through a cultural space: in the everyday 'habitus' of lived experience and in the rituals of public engagement of society. These cultural resources may not be easy to identify, and 'may be differently articulated by men and women, the poorest and the merely poor, the employed and the unemployed, the disabled and the able-bodied, the more politically conscious and the less mobilized... But it is never hard to identify threads and themes in the worldviews of the poor. These are strikingly concrete and local in expression but also impressively general in their reach..." (Appadurai 2004). A case in point is the study of activities in cybercafés in rural Himalayas where users produced visual mashups of themselves with Bollywood stars and self-portrayals as superheroes (Arora 2010). The complex relationship of the poor and the marginalized to the cultural regimes within which they function is clearer still when we consider a specific cultural capacity, the capacity to aspire. As approaches to cultural processes, these frequently remain obscure and prove costly for the poor especially in regard to 
To cite: Rangaswamy, N., \& Arora, P. (2015). The mobile internet in the wild and every day: Digital leisure in the slums of urban India, International Journal of Cultural Studies, 1-16.

development policy and think-tanks. Aspirations certainly have something to do with wants, preferences, choices, and calculations. And because these factors have been assigned to the discipline of economics, to the domain of the market and to the level of the individual actor (all approximate characterizations), they have been largely invisible in the study of culture.

Thereby, our call underlines the role that participatory digital architectures of today can play in enabling these myriad voices of expression and aspiration.

\section{The Slum as a socio-geographic lens}

The primary focus of the paper is the evolution of social media, particularly Facebook, to adapt specific socio-technical practices and technological characteristics for contextual usages, in this case the urban slum. Facebook in the context of use among residents of a slum community pioneers social networking practices beyond the neighborhood, face to face and community based networks. Urban shanty towns or slums in India are essentially resource-poor and digitally-stressed communication ecologies. Some of the questions we wanted to answer were as follows: How do computing technologies, especially the mobile internet, find their way into these communities? Who are the people driving these technologies? How is technology being received by the community?

The multi-dimensional aspects of internet and social media use cannot be discussed in isolation of the slum locality, context, habitats and modes of technology penetration. Both slums in our study are located in metro-core areas. Public transportation and proximity to major commercial 
To cite: Rangaswamy, N., \& Arora, P. (2015). The mobile internet in the wild and every day: Digital leisure in the slums of urban India, International Journal of Cultural Studies, 1-16.

venues, burgeoning city expressways, malls, and multiplex theaters are not too far from the reaches of the slum quarter. The slum quarter is an evolving assortment of small habitats, spatial layouts, and commercial enterprises. B Businesses within this domain comprise smallscale industries like metal workshops and auto spare parts garages, furniture stores, photo studios, fast-food joints, and shops selling small goods such as mobile phones, groceries, appliances, garments or jewelry. A typical home is a 100-200 square feet and many not have attached baths or private bedrooms. Constraints of space and resources force compartmentalization of homes based on activities and functionality - kitchen area, television area, mattress area, storage area, and a washing/water storage area- all housed in a single room or spread between two or three connected smaller rooms ( Rangaswamy 2010)Doors are usually kept open and every home typically has a constant influx of visitors - relatives, neighboring children and adults stopping by. Informal spaces are usually gender segregated: the males huddling in front of mobile phone shops or cheap fast food joints or simply street corners. Women usually congregate around water pumps during hours of water supply when they are out to clean dishes, wash clothes, and bathe kids while performing domestic chores. Young women usually do not hang out but interact more purposively in public spaces. We will revisit the importance of gendered spaces in slum quarters in our discussion section.

Public spaces serve as information hot-spots and despite the strong face-to-face and word-ofmouth channels Mobile phones occupy pride of place to maintain, expand, and regenerate socio-business ties and networks. Privacy comes with a premium and public spaces are those that ironically afford private moments. It is in street corners, shop fronts and cyber cafés where 
To cite: Rangaswamy, N., \& Arora, P. (2015). The mobile internet in the wild and every day: Digital leisure in the slums of urban India, International Journal of Cultural Studies, 1-16.

digital leisure is forged and enacted. The proximity to resources at large of the city, the all-toovisible aura of technology driven city scapes in the form of IT parks, public hoardings, premium malls fuels the hunger for cosmopolitan experiences which finds immediacy through the digital realm. The urban slum is then a dynamic site of diverse experiences operating in the shadow of India's new global economy, a constant flow of marketed ICT products and consumptive aspirations. This paper is more than just a vignette about an urban slum in a certain place; it is situated in our account of examining the rise of ICT affordability, exploring in some depth the nature of the multiple and complex relationship between the virtual and physical self and the challenges/opportunities these give way in the form of leisurely yet serious engagements with and within digital life.

\section{Findings and Discussion}

\section{Reclaiming Facebook as Leisure and Labor}

Our research fields in both Chennai and Hyderabad are less than five sq. kms space of human habitat inside the city limits. The Chennai slum on the southern coast Urur, is mainly residential, adjoins a posh neighborhood, housing 3000 households and a population of 10,000. Much of Urur slum youth have the privilege of living in the margins, absorbing without participating the public culture of a posh Chennai neighborhood. The authors were introduced to some of the youth in the Chennai slum by a young taxi driver they had known for a while. As research progressed some of our participants and research informants led us to many of their peers and to gain access into their neighborhood to understand Facebook practices amongst their 
To cite: Rangaswamy, N., \& Arora, P. (2015). The mobile internet in the wild and every day: Digital leisure in the slums of urban India, International Journal of Cultural Studies, 1-16.

young men and teenagers. Hafeezpet, in the outskirts of one of the major IT parks of Hyderabad, is inhabited by a multi-religious population comprising of low-income classes and a slum quarter. Slit by a highway, it comprises of a mix of households, small commercial establishments, survival economies in the form of small shops, cottage industries, servicing stores and a self-employed human labour force offering diverse economic services. Much of our research entry in Hafeezpet came from the owners of mobile phone shops dotting both sides of the highway. One of them, a 19 year old mobile phone dealer and repairwallah [repair man] transitioned to a primary participant in our research foray. Our study being ethnographic in nature aims to engage deeply with a small sample of users. Hence, from a focused and deep engagement with a set of users, our findings are indicative of broad trends and patterns of behaviors. We employed a variety of qualitative methods, including open-ended interviews, observations of community life, and semi-structured baseline surveys, all aimed at achieving a "thick description" of contexts of technology use. We chose both our field sites, Hafeezpet and Urur, for two reasons: one, it subscribed to a typical unauthorized and informal urban settlement we refer to as slums; second, due to its proximity to the vast public infrastructures that are afforded by global Indian cities like Chennai and Hyderabad.

We adopted two techniques to understand social networking behaviors on Facebook: 1) face to face in-depth interviews with 23 Facebook users in three urban slum communities and 2) qualitative profile building of the same users by an extensive study of their Facebook pages. We conceived and executed our research from March to November 2012 in three socio-geographic 
To cite: Rangaswamy, N., \& Arora, P. (2015). The mobile internet in the wild and every day: Digital leisure in the slums of urban India, International Journal of Cultural Studies, 1-16.

communities, two in Hyderabad and one in Chennai. Our focus was on charting pivotal elements of Facebook use, such as the beginning and the amplification of the use of Facebook, and the unfolding and maturation of skills to press the site to service specific set of behaviors. All except two are male, between 17-21 years of age, from low-economic backgrounds with a family income in the range of 1700-2500 \$US (a monthly income 140-170 \$US). Their educational background varied from school drop outs to college going with some of them working for an average monthly income ranging from 100-200 \$US. An average monthly spending on the mobile internet is around 1 to 3 \$US per person. We investigated the social contexts of our subjects concentrating on the motivations to join Facebook and the paths that led them to the social media site. We further focused on their articulations of behaviors exclusive to Facebook, their friending patterns, what they post and how they share and exchange information, photos and messages. We paid careful attention to their phones, the way Facebook was accessed via applications and clients downloaded specifically for this purpose, their friend lists (making note of the social profiles of their friends) and exchanges that were public on their pages. Next, we made a gallery of all the images that appeared on their pages with an intention to analyze aspects of persona building and representations they signify. From profiling our participants, both on and offline, we gathered a) their social locations, b) what they post, and c) for whom (their sense of audience).

Our research informants accessed social media sites on their modest feature phones and customized them with proliferating technology platforms and applications specifically developed for low cost digital environments. In developed contexts, Facebook has become an 
To cite: Rangaswamy, N., \& Arora, P. (2015). The mobile internet in the wild and every day: Digital leisure in the slums of urban India, International Journal of Cultural Studies, 1-16.

increasingly important tool for people engaging in a range of communication behaviors, meeting information needs and building social capital. Our set of user profiles is no different but their Facebook activity is forged as a path to overcoming constraints of the everyday and has specific consequences for their personal and social expectations of networking on Facebook. Facebook as technology mediating social interactions offered an incredibly powerful channel to overcome the duress of locality and sociality of youth living in the marginalized urban edges of India.

In this community of young adults, social norms seem to accommodate friending strangers and who make up a vast majority of their Facebook friends. Many hoped to make offline friends with online acquaintances. This may be related to the tendency to friend strangers that are local or regional. Similarly, some searched for new friends based on familiar names or were happy to friend request any Indian person. Certainly others mentioned an interest in making friends with people far away, as a teenaged boy put it "... I will look for and friend certain names... Like Jack or John for instance..." For our young informants, Facebook engagements are gateways to unimaginable opportunities: composing second selves, making friendships and forging diasporic interactions. More importantly, underlying all these on-line activities is the urge to seek aspirationally endowing interactions with people from an elevated social status. The latter may range from associating via Facebook with film stars, sports personalities, and fashionistas to body builders, beautiful educated women, non-resident citizens, ethnic diaspora and people of authority. These are articulated in the manner and pattern of Facebook friending, which formed a good part of our study. Looking for romantic 
To cite: Rangaswamy, N., \& Arora, P. (2015). The mobile internet in the wild and every day: Digital leisure in the slums of urban India, International Journal of Cultural Studies, 1-16.

opportunities play a big role in Facebook activity and are dominated by heterosexual dating possibilities aligned with possibilities of upward class mobility via friending women of higher social segments. Facebook pages display behaviors as engagements for better material affordances in the form of socially elevating friendship and heterosexual relations. These behaviors were grounded in specific practices that our informants described as parameters by which they evaluated strangers for a friend request. This evaluation process is a fertile site for examining a user's life world of values, social norms, and romantic expectations from Facebook to fit into these. Searching profile pictures(especially for girls whose profiles tend to be private), photos that are browsable in a Facebook user profile, overall impressions in terms of the profile's socioeconomic class and perceived authenticity were cited as factors in deciding the imagined potential for a friend request. Once sent, some of them, confessed to feelings of vulnerability about the status the request will be subjected to (This emotional response indexes a sense that a friend request carries (at least some) of the anxiety of 'making the first move' in off-line situations). Moving beyond exploring romantic possibilities, star struck users fill their timelines with pictures, quotes, moments from the lives of celebrities simultaneously endowing them with their intimate gaze. Timelines thus transform into a repository of audio visual attestations of celebratory fandom and testaments to one's association with elevated statures. In the absence of infrastructural bandwidth for perpetual digital connectivity and storage, Facebook stands in as an enduring interface for the persistent gaze and affinity with beloved personalities, objects and moments in the life of our user subjects. They, of course, keep their own Facebook profile laid bare for evaluation from their potential friends and declare these 
To cite: Rangaswamy, N., \& Arora, P. (2015). The mobile internet in the wild and every day: Digital leisure in the slums of urban India, International Journal of Cultural Studies, 1-16.

pages as a embodying their 'complete' identity. For future research, it would be interesting to investigate in what sense it captures their 'complete' identities.

Thus user aspirations for Facebook varied widely. They ran the gamut from exploring, making and learning from friends near and far flung across the globe. These young men seemingly play down the importance of Facebook in their lives, as one of them said, "FB is just for entertainment, just like cinema and at max to find out few things, but not for entire life." Even if informants play off their emotional involvement with Facebook-and claim that it is not very compelling they equally let it slip by that they "cannot live without Facebook." This attitude re-orients to an idea of entertainment not as frivolous but as important leisure time in what may be an otherwise demanding routine.

Offline social realities are reflected in the online Facebook interactions, but manifested differently in different users. These socially marginal youth live under highly structured socialization possibilities with young women and the low socioeconomic status affect their heterosexual comportment and dating choices. In some users' experience of Facebook, these social structures reproduced themselves: they socialized online mostly with young men, were unable to change their settings to reflect a romantic relationship, stated that people with darker skin were less likely to use a photo of themselves as a profile picture or felt intensely uncomfortable with pornographic profile pictures certain women friends ( usually fake women profiles) choose to display on their pages It is not unusual for these young men to have hardly spoken with girls in their life. For example, one of our 20 year old informants said, "In the 10th and 12th I never used to talk to girls... even now I don't but before I used to bow my head down 
To cite: Rangaswamy, N., \& Arora, P. (2015). The mobile internet in the wild and every day: Digital leisure in the slums of urban India, International Journal of Cultural Studies, 1-16.

and not answer any questions. After a year of Facebook chatting, I can look at them and speak with them and at least answer their questions before walking off... ". He speaks very candidly about the difference between online and offline social affordances, "On FB, one can talk freely without having any fear... That girl asks me 'come on FB.' She cannot ask me like that to come outside, na... She also uses (informal vocabulary). She may not talk outside at all... it is easier to talk with a girl (friend) on Facebook than in person... Face to face, we cannot really talk anything. If it is FB, we can talk more..." Facebook presents a low-stakes environment to socialize with new people. Our users took the opportunity to befriend and chat with new girls. Even the few who already had a girlfriend found this freedom compelling. One of them admitted "...that even after having found a steady girlfriend I am looking around for more girls as a backup..."

The humble feature mobiles these youth own, afford the ability to do practically anything on Facebook. Accessing Facebook via mobiles is characterized by an economy of time and attention. Everything costs money to access, and even in an unlimited data plan, there is also a time cost to consuming Facebook's image-heavy mediascape. Users have to labor to persist and tease out affordances from the mobile in order to press Facebook into servicing their unbounded desire to rapport with new friends. This interface allows the user to see the most relevant information in sufficient detail (e.g. how many comments have already been posted on a girl's photo), but it does not let you see all information side-by-side, as you would on a desktop computer. The mise en scène of a Facebook profile dissuades our users to be anything but passive. On a phone, it is as though the user has blinders on, viewing the site in 
To cite: Rangaswamy, N., \& Arora, P. (2015). The mobile internet in the wild and every day: Digital leisure in the slums of urban India, International Journal of Cultural Studies, 1-16.

discreet portions, consuming the information ecology byte by byte. Thus enormous dexterity is needed in order to consume the site piecemeal and steadily build an integrated experience out of discreet ones of whatever is the preoccupation, whether romantic, diasporic or otherwise. This results in an altogether different immersive sense of involvement and participation on Facebook.

Several apps and clients are customized on to the mobile screens of users. Some of the core ones are anti-Virus programmes, Core Play for media files, 3G TV which links to streaming media (much of which is porn) and more importantly, Nimbuzz, a messenger for voice and text chats with friends over data. Nimbuzz users can chat directly from their screen names to Facebook chat and the user stays within Nimbuzz, but s/he is plugged into the FB API and can pull in friends from different platforms simultaneously. Using Nimbuzz, especially with short term unlimited data plans, can represent a huge cost savings for the volume of voice and chat messages. The 'favorites' feature allows people to more easily chat with whoever they've added to this list. Facebook does not allow the creation of a friends list but replaces with alerts of friends who are online. In our opinion, the Nimbuzz favorites list could encourage our young users to re-chat girls they might have wanted to be better friends with and speculatively add to the friends list. It is a software/structural feature that encourages relationships to be strengthened over time instead of chatting whichever random stranger happens to be online. These practices get repeatedly fine-tuned and honed to optimize internet as the channel of preferential communication. It also points to a shift towards using the internet as voice and 
To cite: Rangaswamy, N., \& Arora, P. (2015). The mobile internet in the wild and every day: Digital leisure in the slums of urban India, International Journal of Cultural Studies, 1-16.

chat, bypassing the plethora of attractive talk time and SMS plans, particularly serviced to develop and maintain far flung and potentially long term friending relationships.

\section{Kulbeer's Diaspora: Cultivating a Garden}

Building Facebook profiles is an intensely engaging and passionate project in the lives of our research subjects. It is like 'cultivating a garden' as Kulbeer, a 16 year old Sikh boy states, living in a slum in Hyderabad with his father, a truck driver, mother and younger brother. Kulbeer is in high school and had discovered the 'mobile internet' when a friend's friend in a city college talked about this 5 Indian rupees (4 cent) for a day's internet and unlimited download. He soon stumbled upon a plethora of deals from 12 odd telecom national and multinational service providers in his slum. He has a Nokia 5300, brought from the money he earned working in a Pharmacy during the summer and loaded internet on it. "Mental Kartha Hai" or "blowing my mind' is what he said after a few weeks of his micro pre-paid internet usually bought from a careful study of the deal of the day plans floating around the numerous mobile stores in the vicinity. His neighborhood buddies and their buddies, similar aficionados of the internet, get together in the evenings to discuss and customize internet plans, deals, phone features, specifications, web sites offering free downloads of music and videos. Life was happy until Facebook came along and disrupted their contentment! Now, Kulbeer and friends had something in their palms that could connect them outside of their neighborhood, their city, region and country, especially young women unknown to them and their family and community! A time of enchanted exploration followed, searching ways to optimize the phone 
To cite: Rangaswamy, N., \& Arora, P. (2015). The mobile internet in the wild and every day: Digital leisure in the slums of urban India, International Journal of Cultural Studies, 1-16.

and the internet within small means. The desire to befriend forbidden women of higher status and class overwhelmed other explorations of Facebook. Kulbeer initiated his Facebook profile with a photo of a sleeping ginger puppy that soon gave way to a mug shot of his face. He was initially hesitant to plunge into romantic opportunities that the site offered, abetted by his friends who were far ahead in matters of chatting, exploring heterosexual dating opportunities and tagging him in several photos of romantic nature.

Observing and mining Kubeer's pages on Facebook over a period of 12 months yielded an interesting schema of 'cultivating a garden'His site had a repository of photos extolling his ethnic Sikh identity, a sequence of historical junctures in Sikh history, most of them acclaiming a history of heroism, overcoming physical and socio-cultural subjugation, a string of current global news about the Sikh diasporic community and most interestingly, a deluge of Sikh men in various states of physical fitness and show of brawn, bringing a closure to a historical tableaux of Sikh valor and fortitude. He continues to be tagged in his friend's photos sometimes in the Telugu text in contrast to and merrily accompanying his own photos visible on his pages and newsfeeds.

Kubeer's Facebook behavior is a testimony to a mosaic of activities that tie his identity to several layers of personhood drawn from his sense of locality, region, religion and the diaspora. Both, personal volition and an allowance for the preferences of friends are braided by a Sikh teenager living in South India and tenuously associating with the Sikh global diaspora. Kulbeer's Facebook is a measure of his labor for a serious tailoring of identity and enjoyment, however dispersed and manipulative be the sources of influence crafting his Facebook profile. 
To cite: Rangaswamy, N., \& Arora, P. (2015). The mobile internet in the wild and every day: Digital leisure in the slums of urban India, International Journal of Cultural Studies, 1-16.

It also points to a constant pruning of and engagement with technology for perpetual connections, communication and externalizations of self-identity.

\section{Conclusion}

\section{Leisure Geographies of Digital Media}

Kulbeer's garden bearing Diasporic content on his Facebook timeline is presentation of self in on-line networked environments in a complex of SNSs that combine a variety of audiences 'into a single crowd of spectators' observing the same performance, but from a variety of vantage points (Papacharissi 2010. Kulbeer's audience encompass a range of friends and strangers, exotic foreign women and the diaspora from his own Sikh community. Kulbeer is essentially engaging in 'multiple mini performances' to produce his presentation of self, in a space that only Facebook can provide in a form that is accessible, affordable and sustainable.

Localization of Facebook is not simply forging a technical system to match affordable access but a socio-cultural phenomenon resulting from interpreting contexts of use. What slum youth perceive to be Facebook is durably connected to the management of what the SNS offers in relation to what is made available to them in lived contexts. For our informants in the slums of Chennai and Hyderabad, Facebook was not just an object, experience or technology of leisure. It was a gateway, enabled by a socio-technical habitus and 'the elective mobilization of the distant' (Giddens, 1991) into a world inhabited by places and personalities inaccessible without these 'technologies of self'. The consequence of perceiving Facebook as a romantic gateway rests as much on its ability to influence and shape offline personas and their self-perception. 
To cite: Rangaswamy, N., \& Arora, P. (2015). The mobile internet in the wild and every day: Digital leisure in the slums of urban India, International Journal of Cultural Studies, 1-16.

Our user subjects perceive Facebook as an aspirationally romantic gateway and a vesting of affordance that constantly evades their every day. Facebook enabled romance is also a presence mediated heavily through popular cinema attached to the screen personalities of its matinee idols, translating to heterosexual pairing. A Facebook persona therefore is at once dichotomously local/global, rooted/ diasporic and momentous/mundane.

As Miller (2012) points out drinking coke in Trinidad is not to 'import the symbolic meaning of that drink' but 'foreground the primacy of local constructions of meaning'. It seems Facebook was so apt for Trinidad, as a 'Trini' Facebook, amalgamating the culture of Bacchanal, romance and gossip. When our informants say that they discovered their own habitus via Facebook it seemingly allude to the latent even undiscovered, facets of neighborhood, its nooks and crannies and more importantly facets of kinship and friendship. It also seems there is deeper enactments going on with Facebook allegedly vesting magical properties to the everyday. When a 20 year old college student from the Chennai slum said he is able to friend girls on Facebook and hold a conversation, it surely did not exclude the possibility of his experience of 'heterosexual romance' as an act of personal maturation and the imbuing of a romantic personality. That the girls friended and chatted up by Flowking on Facebook belong to an elevated social category provides a whole new edge to subverting entrenched social conventions in the context of the slum's social geography. Conceptually, Facebook provides an expressive space for varied notions of self while also triggering new behaviors rendering the social networking site central to the lives of these youth to acquire agency over their 
To cite: Rangaswamy, N., \& Arora, P. (2015). The mobile internet in the wild and every day: Digital leisure in the slums of urban India, International Journal of Cultural Studies, 1-16.

representations. If Facebook is a composition of 'technologies of self' it suggests a digital entitlement of knowledge, skills, and a worldview.

The goal of this paper is to highlight the centrality of leisure spaces as an active producer of cultures of digital literacies. While development, as we understand it, is not focused on purposive outcomes of informal learning, engagements such as these are a powerful precursor to developing technology literacies, skills and ecologies of learning. To explore every day ICTs for entertainment, pleasure, and play, we touch upon, 1 . How, mundane repetitive everyday use of technology holds tremendous potential for immersive adoption 2 . How, the everyday is dominated by the search for and enjoyment of leisure driven content and 3. How, this separation of leisurely use and developmental use is artificial, and by and large, a facile one.

\section{References}

Appadurai, A (1988), The Social Life of Things: Commodities in Cultural Perspective (Cambridge Studies in Social and Cultural Anthropology), Cambridge University Press

Appadurai, A (2004) The Capacity to Aspire: Culture and the Terms of Recognition, In Culture and Public Action. Rao, Vijayendra and Michael Walton (Ed). Stanford University Press. 2004.

Arcangeli A (2003) Recreation in the renaissance: Attitudes towards leisure and pastimes in European culture. Basingstoke: Palgrave Macmillan.

Arora P (2010a) Dot Com Mantra: Social Computing in the Central Himalayas. Aldershot: Ashgate.

Arora P (2010b) Hope-in-the-wall? A digital promise for free learning. British Journal of Educational Technology 41(5): 689-702.

Arora P and Rangaswamy N (2013) Digital leisure for development: rethinking new media practices from the global south. Media, Culture \& Society 35(7): 898-905. 
To cite: Rangaswamy, N., \& Arora, P. (2015). The mobile internet in the wild and every day: Digital leisure in the slums of urban India, International Journal of Cultural Studies, 1-16.

Arora P and Rangaswamy N (eds) (2014) ICTs for leisure in development: a case for motivation, exploration, and play in the global South. ICTs for Leisure in Development, special issue of Information Technologies \& International Development 10(3): v-vii.

Arora P and Rangaswamy N (2015) Digital romance in the Indian city. In: The City and South Asia. Cambridge, MA: Harvard South Asia Institute.

Bakardjieva, M \& Gaden, G. (2012) Web 2.0 Technologies of the Self, Philosophy \& Technology 25 (3) pp 399-413

Baym N, Campbell, S.W, Horst H (2012) Communication Theory and Research in the Age of New Media: A Conversation from the CM Café , Communication Monographs, 79:2, 256-267

Bell G (2006) Satu keluarga, satu komputer (one home, one computer): cultural accounts of ICTs in South and Southeast Asia. Spring, Design Issues, 22(2) : 35-55

Boellstorff, T. (2008). Coming of age in Second Life: An anthropologist explores the virtually human. Princeton, NJ: Princeton University Press

boyd, d. (2008). Why youth (heart) social network sites: The role of networked publics in teenage social life. In D. Buckingham (Ed.), Youth, identity and digital media (pp. 119-142). Cambridge, MA: MIT Press.

Brewer, E et al., (2005). The Case for Technology in Developing Regions, Computer, June, 25-38

Bruns, A., \& Jacobs, J. (Eds.). (2006). Uses of blogs. New York: Peter Lang.

Bryce J (2001) The technological transformation of leisure, Social Science Computer Review 19(1): 7-16.

Burgess, J \& Green, J. (2009). YouTube:Online Video and Participatory Culture, Cambridge: Polity Press

Castells, M. (2000). The rise of the network society (2nd ed.). Oxford, UK: Blackwell Publishers.

Donner, J. (2009). Blurring livelihoods and lives: The social uses of mobile phones and socioeconomic development. Innovations: Technology, Governance, Globalization, 4(1): 91-101

Doron, A. (2012): Mobile Persons: Cell phones, Gender and the Self in North India, The Asia Pacific Journal of Anthropology, 13:5, 414-433

Fischer CS (1994) Changes in leisure activity, 1890-1940. Journal of Social History 27(3): 453475. 
To cite: Rangaswamy, N., \& Arora, P. (2015). The mobile internet in the wild and every day: Digital leisure in the slums of urban India, International Journal of Cultural Studies, 1-16.

Foucault M (1988b) Technologies of the self. In L H Martin, H Gutman and P H Hutton (eds) Technologies of the self. Amherst: University of Massachusetts Press, pp 16-49.

Ganesh, I. M. (2010). Mobile love videos make me feel healthy: Rethinking ICTs for development. IDS Working Paper 352, Brighton: IDS.

Giddens, A. (1991) Modernity and Self-identity: Self and Society in the late Modern Age, Stanford, Stanford University Press

Goggin, G. (2009). Adapting the mobile phone: The iPhone and its consumption, Journal of Media \& Cultural Studies, Vol. 23, No. 2, April 2009, 231-244

Horst, A H \& Wallis, C (2011) Special Section: New Media in International Contexts Introduction: International Journal of Communication, 5 (2011), 463-470

Ito, M. et al. (2009). Hanging out, messing around, and geeking out: Kids living and learning with new media. Cambridge, MA: MIT Press.

Jenkins, H. (2006) Fans, Bloggers, and Gamers: Exploring Participatory Culture, New York: NYU Press

Katz, J. E., \& Aakhus, M. (Eds.). (2002). Perpetual contact: Mobile communication, private talk, public performance. Cambridge, UK: Cambridge University Press.

Liu, H. (2007). Social network profiles as taste performances. Journal of Computer-Mediated Communication, 13(1)

MacLean R (1968) Television in Education. London: Methuen Educational Ltd.

Miller, D., \& Slater, D. (2000). The Internet: An ethnographic approach. Oxford, UK: Berg.

Miller, D. (2010) Stuff, Polity Press, Cambridge.

Miller, D. (2012) Tales from Facebook, Polity Press, Cambridge.

Mitra, S. \& Rana, V. (2002). Children and the internet: experiments with minimally invasive education in India. British Journal of Educational Technology, 32, 2, 221-232.

Papacharissi, Z. (2010). (Ed.). A Networked Self: Identity, Community, and Culture on Social Network Sites. New York: Routledge. 
To cite: Rangaswamy, N., \& Arora, P. (2015). The mobile internet in the wild and every day: Digital leisure in the slums of urban India, International Journal of Cultural Studies, 1-16.

Rangaswamy N (2009) Telecenters and cyber cafes: the case for ICTs in small business. Asian Journal of Communication 18(4): 365-378.

Rangaswamy N and Nair S (2010) The mobile phone store ecology in a Mumbai slum community: hybrid networks for enterprise. Information Technology and International Development 6(3): 51-65.

Rangaswamy N and Sambasivan N (2011) Cutting chai, jugaad, and here pheri: towards a ubicomp for a global community. Personal and Ubiquitous Computing 15(6): 553-564.

Rangaswamy N and Cutrell E (2013) Anthropology, development and ICTs: slums, youth, and the mobile internet in urban India. Information Technologies \& International Development 9(2): 51-63.

Ritzer, G., \& Jurgenson, N. (2010). Production, consumption, prosumption: The nature of capitalism in the age of the digital "prosumer." Journal of Consumer Culture, 10(1), 13-36.

Salvador T, Sherry J W, Urrutia A E (2005). Less cyber, more café: Enhancing existing small businesses across the digital divide with ICTs. Information Technology for Development, 11 (1) pp 77-95

Sey, A. (2010) New media practices in Ghana, International Journal of Communication, 5, pp 380-405

Sen, A. (1987). Equality of what? In S. McMurrin (Ed.), The Tanner Lectures on human values (Vol. 1, pp. 197-220). Salt Lake City: University of Utah Press.

(1999). Development as freedom. Oxford: Oxford University Press.

Smyth T (2010) Where there is a will, there is a way, Proceedings of the 28th international conference on Human factors in computing systems, ACM, New York, NY, USA

Terranova, T. (2004). Network culture: Politics for the information age. London, Ann Arbor: Pluto Press.

Thompson, M. (2008) ICTs and development studies: Towards development 2.0, Journal of International Development, Volume 20, Issue 6, Pages 727-835

Turkle, S. (1995). Life on the Screen: Identity in the age of the Internet. New York: Simon and Schuster. 